\title{
The ageing of the universities
}

Richard Pearson

\section{Will the present academic staff of universities around the world be able to cope with the challenges of a} new era?

UNIVERSITIES are moving into a new era of static or reducing public funding, a growing relationship with the private sector and consumers (the students), and increased pressure to deliver tangible 'results'.

This all reflects a major change in the philosophy of the decades up to the mid 1970 s, when higher education was generally regarded as a Good Thing in an affluent society. During that period, public money flowed into the system to fund the rising cohort of students, resulting from the post-war baby boom and rising educational attainments, thereby completing a virtuous circle as more higher education led to more economic growth.

Young academic faculty flooded into the system for a decade or more with, for example, the number of professors in West Germany quadrupling, faculty numbers in Australia doubling, and in the United Kingdom growing by a quarter. Then in the mid 1970s expansion ground to a halt; hirings came to a virtual standstill, mobility slowed and the population of faculty grew older together. By the mid1980 s the universities had become middle aged. In the United Kingdom the proportion of young staff, aged under 35 , fell from 37 per cent in 1972 to 17 per cent in 1985. In Germany it fell from 27 per cent (aged under 40) in 1977 to under 6 per cent in 1983, and in Sweden from over 41 per cent to under 25 per cent. This has led to growing concern about the lack of new talent entering the system, and also the loss of the knowledge of a generation of potential academic researchers who have had to pursue their careers elsewhere.

\section{Fading attraction}

The decline in new openings for academics has also lessened the attractions of postgraduate study and research in many countries, leading to an inadequate supply of postgraduate students to meet both current needs and, perhaps more critically, the needs of the next decade. The corresponding growth in the older age ranges (see table) is also seen to have the consequence of lowering staff morale as promotions dry up, creativity stagnates and an apparent wall of retirements builds up which will hit the system at the turn of the century. In West Germany the retirement surge starts rather earlier, with one in five professors expected to retire between 1990 and 1995 . These retire-

ments may well coincide with the downturn in supply. which was set in train a decade earlier.

The late 1970s did, however, see a growing awareness of these impending problems and a number of initiatives have been established to increase the flow of young researchers into the universities. In the Netherlands an important reform was the restructuring, in 1986, of academic staff into three grades and the establishment of fixed ratios of appointments, with 2.5 senior lecturers for each professor. This complements the introduction of

\section{Percentages of staff aged 50 or over}

West Germany

United Kingdom

Norway

Sweden

29 (in 1977) 49 (in 1983)

17 (in 1972) 28 (in 1986)

30 (in 1977) 38 (in 1985)

32 (in 1977) 38 (in 1985)

Source: OECD

AIO or research trainee positions which were introduced in 1984 to provide economic and supervisory support for individuals capable of undertaking advanced research. They involve twoor four-year individually planned programmes which include at least 75 per cent of the time being devoted to research training. Initially 600 posts were created, rising to 5,000 by 1990 . In addition two recruitment programmes, targeted at talented $\mathrm{PhDs}$ aged 25-40, have been launched providing 350 extra postdoctoral research fellowships. These extra posts are being paid for by a successive reduction in the number of senior university posts and the abolition of temporary appointments, whose numbers are planned to fall from just under 2,000 in 1985 to 485 this year.

In the United Kingdom an early retirement scheme was launched in 1981 which, while it created some extra openings, is believed to have resulted in some staff moving to other well paid positions outside the universities rather than out of the labour force. In addition there has been the 'New Blood' programme of nearly 1,000 extra posts which were successfully targeted at staff aged under 35 , with over 90 per cent being under 30 , principally in scientific and technological subjects. In addition 110 temporary posts were created under the Royal Society scheme, initially of five years duration but with extensions for up to a further five years. Finally, additional posts have been created in selected areas such as the new technologies.

\section{Toward the sciences}

In West Germany legislation was introduced to facilitate the creation of nontenured posts in the hope that this would increase staff turnover, while there has also been a redistribution of posts toward the sciences and technologies and away from the humanities and social sciences. Of a more specific nature has been the Heisenberg programme which started in 1977 and is scheduled to run until 1991. Up to 750 five-year awards are available for promising researchers, who were expected to be aged under 33 . In the event 543 awards have been made so far across all the disciplines, and although there was a high level of applications the average age of recipients has been 36 . Among those completing their awards there has been a strong flow into tenured university or other permanent research appointments. Finally, the Fiebinger programme has involved the premature creation of a limited number of tenured university positions between 1985 and 1989 to make extra openings available for young researchers, with a corresponding reduction of posts through retirements in later years.

An interesting early retirement scheme has been introduced in Norway, whereby retirees can not only choose the age at which they leave, but they do not have to leave their home department, maintaining their titles and salaries and being able to devote themselves to full-time research. In addition a number of high priority areas have been targeted in Norway, in the new technologies, to receive a real increase in funding.

The problem of collective ageing is now being addressed in many countries on a selective basis. What is less clear is what is being done to ensure an adequate supply of postgraduates to meet future needs and how academic life can be made more attractive, so that it can match the increasingly competitive private sector as and when recruitment needs soar at the turn of the century.

Richard Pearson is at the Institute of Manpower Studies, Mantell Building, University of Sussex, Falmer, Brighton, Sussex BNI 9RF, UK. 